\title{
A REVISTA EXÍlIO, DE SANTA RITA E PESSOA, E O SEU OCULTISMO
}

\author{
The MAgAZINE EXÍlIO, BY SANTA RITA AND PESSOA, \\ AND ITS OCCULTISM
}

\author{
Pedro Teixeira da Mota"
}

REsumo: O presente ensaio centra-se na revista Exílio na continuidade das publicações Modernistas, especialmente nas suas ligações com Orpheu e Centauro. Para o alcance da proposta dessas relações dialógicas, discutem-se alguns aspectos como: a) a amizade entre Augusto de Santa-Rita, director, e Fernando Pessoa, colaborador e provavelmente um dos ideólogos por detrás da publicação; b) o conteúdo da revista Exílio: colaboradores, artigos e desenhos simbólicos; c) o editorial ou Justificação e as suas linhas de força espirituais; d) alguns aspectos ocultos e esotéricos na obra de Augusto Santa-Rita e Fernando Pessoa, em especial nos textos e poemas de ambos na Exílio; e) o artigo final de Fernando Pessoa, como mestre do movimento Sensacionista, com as suas tendências esotéricas, e crítico e instrutor de dois jovens poetas sensacionistas; f) a ideia de missão e do "É a Hora", agora; g) a Tradição Templária na Exílio, em Augusto de Santa-Rita e em Fernando Pessoa.

Palavras-chave: Exílio, Augusto de Santa-Rita, Fernando Pessoa

AвSTRACT: The presente paper focuses on Exilio magazine in the continuity of Modernists publications, specially in its relations with Orpheu and Centauro. To reach the proposal about these dialogical relations, we discuss some aspects such as: a) the friendship between Augusto Santa-Rita, the director, and Fernando Pessoa, collaborator and probably a master mind beyond the publication; b) the contents of the magazine Exilio: the colaborators, the articles and the symbols; c) the editorial or Justification, by Augusto Santa-Rita, and its spiritual lines of force; $d$ ) some occult and esoteric aspects in the works of Augusto Santa-Rita and Fernando Pessoa, specially in the texts and poems of both of them in Exilio; e) the final article by Fernando Pessoa, appearing as the master of the Sensacionist movement, with its esoteric trends, and critic and instructor of two young sensacionist poets; $f$ ) the idea of mission and "it is the Hour", now; g) the Templar Tradition on Exílio, Augusto Santa-Rita and Fernando Pessoa.

Kerwords: Exílio, Augusto de Santa-Rita, Fernando Pessoa

\footnotetext{
"Pesquisador independente no espólio de Fernando Pessoa na Biblioteca Nacional de Portugal, Portugal, e autor de quatro livros de inéditos em 1988 e 1989: Moral, Regras de Vida e Condições de Iniciação, Grande Alma Portuguesa, Rosea Cruz.E-mail: viva.erasmo@gmail.com.
} 
A revista Exílio é dada à luz em Abril de 1916, poucos meses depois do brilho da revista Orpheu ter começado a desvanecer-se, talvez como outra onda do mesmo mar ou para assinalar uma continuidade tripla, de geração, de ideologia e de individualidades, pois tem como fundadores três membros de Orpheu, Pedro de Menezes (pseudónimo de Alfredo Pedro Guisado), António Ferro e Armando Cortes-Rodrigues, além de Augusto Santa-Rita que será o único director.

Ela surge como um contraponto, uma síntese entre Orpheu modernista e europeísta, $o$ ambiente que a acolhera com grande alvoroço, incompreensão e irritação e as outras potencialidades afectivas, culturais e espirituais da mesma geração portuguesa...

O sumário na primeira página do número 1 e único discrimina os vários artigos e colaboradores, destacando-se neles a Justificação inicial por Santa-Rita e o artigo final de Fernando Pessoa, pois além do poema "Hora Absurda", participa com um texto doutrinário e de crítica, no qual veícula certos aspectos ocultistas, nomeadamente quanto ao modo como via então o seu grupo e movimento, país e época.

A relação de Fernando Pessoa e Augusto Santa-Rita, nascidos no mesmo ano de 1888, foi amistosa, embora só haja anotações no Diário pessoano de 1913 assinalando a amizade e os encontros que tinham no Chiado, mas não nos surpreende que ao longo dos anos ela se tenha mantido, tanto mais que Augusto Santa-Rita se interessava também pelo Ocultismo, algo essencial no percurso de Fernando Pessoa.
Assim nesse mesmo ano de 1916, mas já em Setembro, Fernando Pessoa em carta a Armando Cortes-Rodrigues, depois de dizer que Orpheu 3 em breve estaria nas bancas, referia que de importante literariamente só havia a registar, além do Manifesto anti-Dantas de Almada Negreiros, a Luz Poeirenta de Silva Tavares, dedicado a ele, e as Praias do Mistério de Augusto de Santa-Rita.

Quando lemos com mais cuidado ou sensibilidade a Justificação prefacial de Augusto Santa-Rita observamos palavras que podem ter por detrás ou no seu interior dimensões ocultas à primeira vista ou leitura e serem portanto referenciais de conhecimentos ou doutrinas esotéricas.

Assim, diz-nos Augusto Santa-Rita na Justificação ou seu manifesto da revista, a nova geração literária assume-se "como Cristo", isto é, como ungida para se sacrificar em «calvário de Beleza», para assumir a sua independência ou "autocracia moral" de modo a impor "à massa amorfa de um povo de inconscientes emotivos um novo credo, irritante sem querer" (1982, p.5).

Mas esta geração antes de apregoar a sua mensagem (e seria bom sabermos se a Justificação também teve algum dedo pessoano...) confessa a sua linhagem, a sua pertença à Tradição Cultural Espiritual Portuguesa (por vezes, pequenamente interpretada como nacionalismo), que tem passado os seus motes e ritmos ao longo dos séculos através dos poetas, identificados a aves que cantam às mulheres e mães, as quais depois os ensinam e transmitem. Alguns seres são mesmo evocados, "Senhor Rey D. Dinis, Camões e Bernardim, Crisfal, 
Bocage e Tolentino, Antero, Cesário Verde, António Nobre e tantos outros rouxinóis".

"Qual outro menino Deus", como "novo Cristo do Ideal", a geração e revista "revelará o céu que existe aquém das nossas almas", "despertará do seu sono mortal as coisas imortais", "curará os leprosos da Ignorância com a fé em seus merecimentos", "ela emprestará a luz magnífica dos seus olhos aos que vivem nas trevas da Inconsciência", "ela matará a sede e a fome de beleza com o milagre do seu Génio", "o seu lema é de Paz, de Amor e de Beleza".

Esta Justificação prefacial, bem cheia de aspirações espirituais, parece implicar algum conhecimento esotérico que sabemos já estar razoavelmente desenvolvido em Fernando Pessoa, desde a adolescência a ler boas obras e algumas de esoterismo e que em 1915 começara a traduzir do inglês obras de Teosofia para a editora A. M. Teixeira.

Quanto a Augusto Santa-Rita também o detinha, pois em 1912 publicara as Árias, Rezas, Canções e Cantares, e em 1916 as Praias do Mistério, onde o seu conhecimento do mundo astral e dos Anjos manifesta-se, embora seja em 1925 que ele mais plenamente transmite elementos ocultistas com o Auto da Vida Eterna, no qual encontramos entre as personagens tanto o Anjo de cada um dos intervenientes principais como também o seu corpo astral, o que implica o conhecimento da existência, ou da doutrina, dos vários planos ou mundos, tais como por exemplo Fernando Pessoa apresenta "etérico, astral, mental, espiritual e monádico” (Esp. F. P. 53A-46, in Rosea Cruz), ou mais resumidamente "o astral, o mental e o espiritual", e dos seres celestiais correspondentes a eles, algo que Fernando Pessoa também muito especulou, nomeadamente na linha das nove ou dez hierarquias angélicas que tanta voga tiveram no Ocidente desde que o pseudo-Dionísio Aeropagita as delineou ou criou, numa linha das emanações neo-platónicas.

Podemos perguntar, nesta Justificação ou apresentação do projecto, o que se consubstancia como o «céu que existe aquém das nossas almas»? Preferiu o aquém em vez do além, para marcar uma proximidade dinâmica? Será o plano astral luminoso ou mesmo o espiritual, ou será apenas o desejo, o sonho, a utopia?

Estará ele ligado com o despertar do sentido de imortalidade que acordará as pessoas, que as retirará da ignorância em relação aos seus merecimentos e à fé viva que se deve ter neles? Ou este céu está ligado mais à luz espiritual e à verdade as quais, ao começarem a irradiar dos olhos, vencem a obscuridade da ignorância inconsciente e desvendam o mundo espiritual e divino?

Está Augusto de Santa-Rita a apelar a um vero despertar espiritual, a um assumir do corpo espiritual, ou seja de uma alma que se reconhece como corpo espiritual consciente e irradia luz e amor pelos olhos físicos e subtis?

Ou apela ele ao despertar da genialidade de cada um, à capacidade de revelarmos novas formas artísticas e de beleza?

E o que é ou quem é o Génio, referido por Santa-Rita e que também interessou bastante Fernando Pessoa, levando-o a escrever inúmeras páginas, muitas delas relacionando-o com a iniciação, com as metodologias 
ou caminhos iniciáticos para ele, seja como o espírito de cada um, seja como o mestre ou mesmo o Anjo de cada ser.

Será para Augusto de Santa-Rita "o milagre do seu génio” a assunção da missão divina de cada um, e a da geração a que pertenciam "os novos que confiam ainda no Ressurgimento de Portugal"?

Cremos bem que sim, pois a missão da revista será "de Paz, de Amor e de Beleza", levada no "estandarte da nova Geração", e é "Bandeira a cujo pano um punhado de soldados do Pensamento, gritará a victória dos seus ideais" (1982, p.6).

Porquê o nome de Exílio, perguntar-se-á? Para além de provir do sentimento de desfasamento em relação ao meio ambiente daquela geração, também já na revista Orpheu tal fora bem acentuado na Introdução por Luís de Montalvor: "Puras e raras suas intenções como seu destino de Beleza é o do:-Exílio! Bem propriamente, ORPHEU, é um exílio de temperamentos de arte que a querem como a um segredo ou tormento..."(1971, p.11).

Aflorará igualmente na revista Centauro, publicada também nesse ano de 1916, com o seu director, de novo Luís de Montalvor, escrevendo no programa ou primeiro artigo da revista, Tentativa de um ensaio sobre a Decadência:

Somos mais sentidamente decadentes porque somos mais misticamente doentes que todos os místicos de todas as doenças espirituais de todos os tempos. A decadência é para nós o símbolo com que vestimos o estado de alma colectivo de exilados da Beleza!... (1982, p.8. Destacados do autor)
Mas na Exílio surge talvez mais como exilados de uma primordialidade ou unidade divina, pois a primeira ideia e linha da Justificação aponta para uma consciência genésica e primordial: "Saudosa do Pomar de Maravilhas que foi e será sempre Portugal, a cuja sombra o Senhor Rey D. Dinis, Camões e Bernardim, Crisfal, Bocage e Tolentino, Antero, Cesário Verde, António Nobre e tantos outros rouxinóis cantaram..." (1982, p.5).

Este Pomar das Maravilhas com que se designa Portugal pode ser visto como o Pomar das Hespérides, o jardim mítico das maçãs de ouro da imortalidade guardado por uma serpente e seres negativos e que Hércules nas suas provas iniciáticas vencera. À sua sombra vê então Augusto Santa-Rita os imortais poetas portugueses, os rouxinóis perenes fecundando nos seus cantos as mães e assim passando de geração em geração seus conhecimentos e sensibilidades. E por isso o último parágrafo da Justificação aponta para o Futuro, assim se desenhando o anel da eternidade consciencializada e demandada: "Exílio: - será finalmente a linda praia em desterro para onde voluntariamente se expatriaram todos os que, independentemente de cor política, confiam ainda no ressurgimento de Portugal pelos novos" (1982, p.6)

Realcemos então esta confiança numa acção despertante, clarificante e libertadora (supra-política...) a que a nova geração se sente chamada e à qual a revista tentará apelar. Com que consciência do seu sucesso ou, pelo contrário, da sua efemeridade, é infelizmente difícil de discernirmos hoje pela escassez de documentos e testemunhos, bem ao contrário de Orpheu que tentava então ainda 
editar o seu número 3, mas que a morte de Sá Carneiro, o principal financiador, em 26 de Abril de 1916, faria com que o só viesse à luz décadas depois, em 1984. E que, embora terminada como revista, não findasse seu nome e psicomorfismo de geração, augurando-se imortal em sucessivas avatarizações imaginadas pelo amor criativo que unia os seus membros e geração, como tanto Fernando Pessoa e Almada Negreiros afirmaram e escreveram, nomeadamente Fernando Pessoa na apresentação do número 3 e último da revista Sudoeste, de Novembro de 1935, dirigida por Almada, com o texto Nós os de Orpheu, onde depois de criticar levemente CortesRodrigues por se estar a embrenhar demasiado no catolicismo campestre, termina com o enfático: “Quanto ao mais, nada mais. Cá estamos sempre. Orpheu acabou, Orpheu continua". Mas certamente a referência mais bela ou icónica foi no poema que em 1934 dedicou ao seu grande amigo Mário de Sá-Carneiro em que sonha "nesse número de Orpheu que há-de ser feito com rosas e estrelas em um mundo novo".

Tendo em conta o que por essa altura Fernando Pessoa entendia como "exotérico, o que pertence à aparência do mundo, esotérico, o que pertence à realidade que está por detrás desta aparência” (Esp. FP. 54A-76), resumamos muito brevemente os vários contributos e relacionando-os com a missão-projecto da revista e o ocultismo e esoterismo que nela e na geração singravam.

O Alfredo Pedro Guisado, já consagrado como poeta paulista e decadentista em Orpheu, colabora com quatro sonetos onde canta ao de leve o que refere no título, $O$
Medo de Satan pela noite, e sabemos a curiosidade ou a atração por essa figura de marginal ou do Mal por parte de muitos dos simbolistas, decadentistas e modernistas, e entre nós poderemos referir Alberto Osório de Castro, Alfredo Pedro Guisado, Raul Leal e Fernando Pessoa.

Com a colaboração seguinte, histórica e de Teófilo Braga, confirma-se que a revista Exílio, na soma e síntese psicomórfica dos seus colaboradores, é bem menos europeísta e modernista que Orpheu, pois abrange bastante mais o passado e a história que o modernismo, ultra-simbolismo, decadentismo, sensacionismo e o futurismo dos membros de Orpheu.

Esta abrangência é como que um meio termo entre as forças do passado e do futuro, entre a tradição cultural antiga portuguesa e a nova e modernista, e nesse aspecto Exílio é altamente significativa e meritória, e não será por acaso que ela surgindo um ano depois de Orpheu, uns meses antes da Centauro e antes do Portugal Futurista tenha, entre os vários colaboradores, o pontífice ou construtor de pontes Fernando Pessoa a assinar o artigo final, cheio de confiança no movimento sensacionista, visão que aos poucos irá contudo abandonar ao aprofundar mais a via ocultista, bem patente na sua poesia ortónima, na qual assinará bem valiosos poemas de cariz oculto, templário e iniciático.

O entrosamento com o passado está então bem patente na segunda colaboração, a do publicista e trabalhador infatigável das Letras e da República Teófilo Braga, que fora ainda amigo do já mítico Antero de Quental, partilhando um excerto do livro Seiscentistas, 
a sair, sobre o tema "Braganças e Jesuítas. A Restauração de Portugal”, onde talvez convenha realçar-se a nota exilada com que termina o artigo, em grande parte sobre o Padre António Vieira:

Vieira regressara a Portugal em 1675, mas na corte tinham medo dele, como declara o conde da Ericeira: "o seu juízo era superior e não igual aos negócios”; e tratava-os "mais subtilmente do que o compreendiam os outros príncipes e ministros". Nestas subtilezas consistia o jogo da Companhia; por isso, como ele já nada aproveitava aos interesses da corporação, foi atirado para o canto... (1982, p.12)

Em seguida é Fernando Pessoa a contribuir com um poema já de há três anos, "Hora Absurda”, bastante decadentista e tingido de desalento, de paúlismo, de absurdo e desistência, acentuando esta tonalidade na Exílio, com as vagas sensações-intuições espirituais, tal como a já germinante e pressionante: "É em mim... Sou a Hora, / E a Hora é de assombros...", ou outras mais de imagens imaginadas do que de ideias verdadeiramente sentidas ou vividas: "a minha alma é uma caverna enchida pela maré cheia", "Deitam-se nuas ao luar/ Todas as ninfas (...)", ou ainda que "o meu ouvir o teu silêncio não seja nuvens que atristem/ O teu sorriso, anjo exilado (...)", finalizando com " $E u$ fui amado em efígie num país para além dos sonhos...”.

O contributo, nos antípodas, de António Sardinha, um integralista e tradicionalista dos valores católicos e nacionalistas, é um poema ao valor da luta, da batalha, do sangue, pela Pátria, e em comunhão com os antepassados e os santos, de certo modo o corpo místico de Portugal, sem dúvida uma doutrina e psicomorfismo persistente e fundacional da Tradição Espiritual Portuguesa, ainda que aproximável de diversos modos, alguns muito belos do próprio Fernando Pessoa (caso do poema "Quinto Império"), ou mesmo de Augusto de Santa-Rita, que já no findar da sua vida, em 1952, no caderno $\mathrm{n}^{\circ} 1$ das Produções Literárias, consigna para a posterioridade esta mesma ideia-força de um modo original:

Fazer versos não é um simples entretenimento como, por exemplo, fazer ou decifrar palavras cruzadas. É uma nobre missão, um apostolado que se cumpre por uma imposição terminante $\mathrm{da}$ própria existência espiritual, depois de muito experimentada pelo sofrimento de sucessivas gerações ancestrais.

Ao entrarmos nos três sonetos de Augusto Santa-Rita, escritos em 1915 e 1916, deveremos considerar a parte artística da revista, bem impressa nos caracteres e nas grandes margens, pois o poema Signal da raça (que, embora sendo o último a ser escrito, quem sabe se para a revista, será o primeiro no tríptico), está impresso sob um desenho da cruz da Ordem de Cristo, a qual já fora apresentada na capa e frontispício, então com quatro flores de cinco pétalas e desenhadas sob certo esoterismo, quem sabe mesmo se evocando a tradição Rosacruz, mas que não está assinada, devendo contudo pelo estilo ser de Jorge Barradas.

Com feito esta cruz da Ordem de Cristo próxima da Templária, pois os braços são iguais só tendo uma cruz branca vazada no 
centro, tem nos seus quatro cantos internos uma flor de cinco pétalas e cremos ser uma rosa, sempre com o centro de cor mais escura ou sanguínea, nas flores de cima, sendo a outra ígnea a do exterior, enquanto que nas inferiores é a pétala mais próxima da circulação axial na coluna que está vermelha ou escura. Haveria em Jorge Barradas algum conhecimento de mandalas, de circulação de energias e da simbólica Rosacruz, ter-lhe-ia sido tal transmitido e encomendado (sobretudo a Cruz de Cristo) por Augusto de Santa-Rita?

Já no desenho do poema "Signal da raça” (1982, p.21), a cruz está dentro de um brasão ou escudo e tem ao centro dessa cruz branca um pequeno sinal de cruz. E não haverá a inserção de outros símbolos pictográficos na revista, podendo então realçar-se a essencialidade mandálica cruciforme escolhida, que leva mesmo as letras do título e a cruz de Cristo a estarem dispostos em cruz e quase num sentido ascendente, no qual a palavra mais horizontalizada Exílio faz de braço transversal e de certo modo de consciência de ausência que aspira ao nível espiritual simbolizado pela Rosea Cruz divina no alto.

Voltando agora aos elementos e psicomorfismos dos seus poemas, Augusto de Santa-Rita fala-nos da origem anímica Portuguesa como vinda do Mar e da paisagem, ou seja, da terra, donde se evola a espiritual aragem que gera, no caso particular, os verdes olhos da amada.

Nos olhos dela perpassa a grande Alma Portuguesa e certa luz, sonho e reza. Antero de Quental, por exemplo, e um dos invocados como rouxinol na Justificaçãa, entre muitos outros poetas e cantadores anónimos, exaltou também a comunhão que os olhos contemplados reciprocamente permitem e a luz que deles se irradia, ou como Augusto de Santa-Rita exprime: "Eis porque o teu olhar no meu influi".

A tradição lírica e cortês do amor dos Trovadores, ou ainda a Tântrica oriental, desenvolveram bem este olhar iluminante e espiritualizante, expansivo da consciência, aqui em Augusto Santa-Rita capaz de causar até a pitagórica e neo-platónica anamnese, a lembrança de um estado anterior a este, seja o de uma outra vida, seja a reminiscência de um estado de Unidade ou de ligação à Divindade, anterior à queda no corpo físico, não especificando bem Santa-Rita no que crê ou intui: "Teus olhos são espelhos d'outra-Idade/ Onde me vejo no que eu d'antes fui!".

Vemos assim como estes poemas estão algo tingidos pela aspiração de Amor e de Gnose, de Universalidade e de Unidade que constituíam de certo modo o eixo axial de demanda e força dos Templários, da Ordem de Cristo e de Portugal, que Augusto Santa-Rita evocou na capa, poesia e revista e que Fernando Pessoa tanto trabalhará em múltiplos textos e poemas, dos quais convirá destacar o do "Quinto Império", do qual extraímos duas quadras:

E outros, e outros, gente vária, Oculta neste mundo misto. Seu peito atrai, rubra e templária, A Cruz de Cristo.

Glosam, secretos, altos motes, Dados no idioma do Mistério Soldados não, mas sacerdotes, 
Do Quinto Império. (PESSOA, 1999, p.98)

O segundo soneto de Augusto de SantaRita, intitulado "Tua Presença” (1982, p.22), é belo e profundo, transparecendo de novo conhecimentos de teorias ocultistas e certa sensibilidade astral. Oiçamos a $1^{a}$ quadra:

Sozinho!... É noite... A voz de Deus me embala

No murmúrio do vento! e eu rezo e eu digo:

- Que de mistérios o Silêncio cala!

- Que deuses cismarão em meu postigo?!

Destacaremos tanto a entrada subtil da palavra ou voz da Divindade no murmúrio do vento, embora não se possa discernir se é apenas o vento que é sentido como voz de Deus, ou se é a voz de Deus que se ouve no vento (e lembremos que neste ano de 1916 Fernando Pessoa traduzia a Voz do Silêncio), como também o autor do poema dialogar com o ser Divino, orando, interrogando, pondo-se na expectativa de receber a hierofania ou teofania que se possa manifestar no seu postigo.

Que Deuses serão esses? Há um certo Paganismo que também ressoava em Fernando Pessoa, que disse mais de uma vez que os deuses não se tinham ido, nós é que os deixáramos de ver, e será que Santa-Rita percepcionava visonariamente, ou acreditava nessas faces da Divindade, bem mais ricas que as permitidas pelo monoteísmo Hebraico e Islâmico, ou o trinitário Cristão?

Que postigo sentiu ou assumiu Augusto de Santa-Rita? O da alma, o do coração espiritual, o do $3^{\circ}$ olho, o do seu ser ou mesmo o da sua casa?

Nas quadras seguinte ele descobre que a passagem da amada pela sua sala despertou novos sentidos nas próprias paredes que sonham com ela e que comunicam com ele. Mais do que o intersecionismo, que se poderia apontar no cruzamento de consciências diferentes e acima do espaço-tempo normal e que está presente, relevemos a influência recíproca entre o observador e a coisa observada, que hoje em dia a Física moderna cada vez mais reconhece no mundo dos quanta, das partículas e ondas, mas que é um dado da Tradição Perene, denominado na Raja Yoga de samadhi, ou unificação do sujeito e o do objecto contemplado, e que é levado a um belo interseccionismo no terceto final, quando confessa que o seu receio "É que um dia adormeças tu por elas/ e elas acordem, meu Amor, por ti!".

O último soneto é também de um revolucionarismo esotérico interessante pois, na segunda década do séc. XX ainda tão marcada em Portugal pelo Catolicismo conservador e algo obscurecedor, Augusto de Santa-Rita inicia a sua amada no verdadeiro céu que está nela, à volta dela e neles e, sem entrar sequer no normal sentimento que se gera no amor humano expresso nos beijos ou na união carnal, Augusto de Santa-Rita entra na recriação do estado celestial que cada ser naturalmente tem e vive e que se intensifica mais quando duas pessoas o reciprocam. Será com pormenores astrais de cores e calores, tanto dos olhos como dos céus, estes sendo, mais do que os exteriores atmosféricos, os das nossas auras e almas. Refira-se que na sua vida 
Augusto Santa-Rita encontrou a sua bem amada, Graciette Branco e que foram muitos fecundos, em especial em contos de amor e moral para as crianças, muitos escritos para o famoso Pim Pam Pum, suplemento infantil do Jornal O Século desde 1925 (o qual dirigiu 15 anos) e que tanta criançada alegrou e educou, nomeadamente com os desenhos de Eduardo Malta e depois de Rodriguez Castané.

Os dois últimos tercetos são bem significativos da sensibilidade ao corpo e plano vibratório astral, mais subtil que o físico e que o interpenetra e rodeia, com que ele SantaRita vibrava e que anos mais tarde Fernando Pessoa elogiará quando aquele publica em 1925 o Auto da Vida Eterna, saudado como uma das primeiras manifestações das doutrinas do Ocultismo na Literatura Portuguesa, nomeadamente no conhecimento do corpo astral, embora tal já estivesse presente no Orpheu, como aliás Fernando Pessoa escreve no texto que fecha a Exílio, ou Luís de Montalvor refere já na fundação de Orpheu: "Nossa pretensão é formar, em grupo ou ideia, um número escolhido de revelações em pensamento ou arte, que sobre este princípio aristocrático tenham em ORPHEU o seu ideal esotérico e bem nosso de nos sentirmos e conhecermo-nos" (1971, p.11, destacados do autor), e que Raul Leal, Almada Negreiros e Augusto Ferreira Gomes, por exemplo, também conheciam e transmitiam.

Diz-nos, então, Augusto de Santa-Rita, nos tercetos de "Céu":

- Há Céu em teu redor, bem o sinto eu, Quando à janela, para ver-me, assómas! Se corro para ti entro em teu Céu
E deixo Céu atrás de mim quando passo!

- Há Céu nas atitudes que tomas

E até há Céu nos versos que eu te faço!

Esta celestização da vida plena, corporal e anímica, pode ser meditada e compreendida esotericamente pelo seu dinamismo astral de campos de força áuricos, e pode ser até equacionada ao estado de Graça da Tradição ocidental Cristã, e para o qual o Amor é a porta, o Espírito Santo que une e reintroduz-nos no céu, isto é, numa frequência vibratória intensificada, ligada mais ao espírito, à unidade e felicidade divina. E veríamos então Augusto de Santa-Rita como um certo rectificador do Catolicismo, tal como algo disso perpassa na colaboração de António Ferro, atraído por um dos imãs mais eróticos e sublimados do Cristianismo, Maria Madalena, e assim de novo se manifestando a missão abrangente da Exílio de clarificar o inconsciente colectivo nacional.

Hoje em dia o reconhecimento cada vez maior que somos unos com o Campo unificado de Energia Consciência Universal e que das nossas partículas muitas vieram do Sol e do Cosmos e que a Música das Esferas pitagórica ressoa omnipresente, auxiliar-nos-á a compreender melhor Santa-Rita quando sente que "Há Céu em cada rua, em cada esquina,/ Em volta de uma abelha ou de uma flor. // Há Céu em tua boca e na menina/ Dos teus olhos, tão cheios de calor, / - Há céus azuis, há ceus de cor mais fina/ E há céus até a que se ignora a cor", isto é, os céus dos níveis subtis e espirituais que nos envolvem...

Não iremos rever os textos todos da Exílio, pois teríamos de ser breves e 
imparciais ou superficiais, mas anotemos ainda assim, no seguimento das páginas da revista, o texto do médico António RitaMartins, dedicado a Almada Negreiros, de memórias de um espelho, algo ressoante das reminiscências e reincarnações humanas. O poema de Martinho Nobre de Melo, onde se entusiasma com um pôr-do-sol que o faz imaginar mil formas e metamorfoses e tornar-se Nero: "incendiei de poente uma cidade inteira.../ Quimera de crear!/ Oh única quimera verdadeira!" (1982, p.29). Por fim "tudo se esfuma e apaga em torva escuridão (...) tudo era sonho e névoa de mim mesmo/ - vento eu sou! meu castelo era também de vento./" (1982, p.30). Encontramo-nos no carpem diem, na transitoriedade da vida e das suas manifestações num certo considerar do mundo irreal na linha oriental...

De Armando Cortes-Rodrigues a "Via Sacra", composta de quatro sonetos, de António Ferro, a Canção de Madalena, bem ousada na época, pela equiparação que faz de Madalena e de Jesus e contornos tanto eróticos como de Amor universal, os artigos históricos e etnográficos de Joaquim Leite de Vasconcelos e Cláudio Bastos, e as breves crónicas de Teatro e de Arte de Victoriano Braga e António Ferro, precedem o que nos interessa mais, o artigo com que a Exílio se encerra intitulado Bibliographia, seguindo-se-lhe o sub-título Movimento Sensacionista. Seis parágrafos de revisitação amplificante ou mitificante do Orpheu e do Sensacionismo, com referências algo esotéricas, seguindo-se a apreciação aos defeitos e qualidades de dois poetas seus amigos, cujas obras são consideradas manifestações do Sensacionismo.
O primeiro é Pedro de Menezes, ou seja, Alfredo Pedro Guisado, realçando nele Fernando Pessoa "a profunda intuição metafísica que socleia tanto os versos culminantes dos sonetos (...) como bastas vezes, a direcção anímica de certos sonetos integralmente" (1982, p.47). Estas críticas são de certo modo de teor esotérico, pois mostram a capacidade de intuír os níveis suprafísicos e espirituais e de, com tais intuições, conseguir dinamizar as forças anímicas na direcção correcta.

Fernando Pessoa aponta-lhe todavia dois defeitos, primeiro, deficiência de musicalidade e de sedução rítmica pura, segundo, o de que "por vezes o poeta esquece as leis, não só exotéricas, mas esotéricas também, da associação de ideias desconexas, e juxtapõe imagens que, sendo, quase sempre, cada uma delas belas, não se fundem em beleza, não se sintetizam sugestivamente no espírito" (1982, p.47).

E é importante vermos a exigência de atenção a um equilíbrio composicional imagético não só formal (exotérico) mas também ao nível esotérico ou interno, dando a entender que a intromissão de figuras históricas (e talvez desarmonicamente) faz sair do nível indefinido, de sonho e de abstração, palavras estas que correspondem a planos níveis ou sentidos subtis e ocultos, que não são bem avaliados nem conjugados na sua dinâmica poética por Alfredo Pedro Guisado.

Na crítica ao segundo poeta, João Cabral do Nascimento, mestre Fernando Pessoa depois de realçar que "os elementos componentes da inspiração sensacionista estão ainda inaharmonicos e inindividualizados" por se tratar de um principiante, descontando 
“a ligeira e indefinível incerteza que há em todos os primeiros passos, físicos como psíquicos", e nestes dois níveis de novo podemos discernir o exotérico e o esotérico, dá um conselho final que é também de profunda ligação espiritual:

Procure o sr. Cabral do Nascimento ter sempre este facto tão presente, que não saiba que o tem presente - que uma obra de arte, por dispersa que seja a sua realisação detalhada, deve ser sempre uma coisa una e orgânica, em que cada parte é essencial tanto ao todo, como às outras que lhe são anexas, e em que o todo existe sinteticamente em cada uma das partes, e na ligação dessas partes umas às outras. Compreenda isto até à inconsciência. Sinta isto até não o sentir. E, sentido e compreendido isto até com o corpo, despreze todo o resto. Salte por cima de todas as lógicas. Rasgue e queime todas as gramáticas. Reduza a pó todas as coerências, todas as decências, e todas as convicções. Feita sua aquela, a única regra de arte, pode desvairar à vontade, que nunca desvairará; pode exceder-se, que nunca poderá exceder-se; pode dar ao seu espírito todas as liberdades, que ele nunca tomará a de o tornar mau poeta.

O resto é a literatura portuguesa.

FERNANDO PESSOA

Sensacionista (1982, p.48)

Estes conselhos dados genialmente a João Cabral do Nascimento por Fernando Pessoa são verdadeiramente uma das suas receitas de iluminação ou, se quisermos, de perfeição, de libertação, que por vezes ocorrem na sua obra, quais pérolas, e a vários níveis, desde os mais exotéricos, de sucesso no quotidiano ou no comércio aos mais subtis poéticos e aos mais esotéricos da iniciação e realização espiritual. Podemos resumir os conselhos ou regras de vida e criatividade à mensagem: "Auto-conhece-te no Todo e em tal iluminação, assimilada e cultivada, sê e vive criativa e corajosamente".

O que há todavia nestes conselhos de mais esotérico? Talvez o salto consciencial, da parte desconexa, para o Todo que está em cada uma das partes, a expansão ou alargamento de consciência, criativamente, supra-racionalmente. Isto é tanto Física moderna, com os Hologramas e os Fractais, como a Mística e a Filosofia Perene dos antigos e do Oriente. E que se deve assimilar em todo o corpo e ser, compreendido e levado até às profundezas do inconsciente.

Esta dupla realização de abrangência exterior e de unificação interior é profundamente esotérica, ocultista e espiritual, pois implica uma assunção do ser e corpo espiritual integrados e consciencializados da sua unidade e da unidade com tudo e todos, o que se desgina também por emaranhamento das mentes no Campo unificado, ou comunhão no corpo místico da Anima Mundi...

Podemos relacionar estas asserções com um escrito não datado de Fernando Pessoa e publicado nas Páginas Íntimas e de Auto-interpretação, no qual dá como o $1^{\circ}$ dos três princípios da arte o seguinte:

1. ${ }^{a}$ - Toda a arte é criação, e está portanto subordinada ao princípio fundamental de toda a criação: criar um todo objectivo, para o que é preciso criar um todo parecido com os todos que há na 
Natureza - isto é, um todo em que haja a precisa harmonia entre o todo e as partes componentes, não harmonia feita e exterior, mas harmonia interna e orgânica. Um poema é um animal, disse Aristóteles; e assim é. Um poema é um ente vivo. Só um ocultista, é claro, é que pode compreender o sentido dessa expressão, nem é permissível, talvez, explicá-la muito detalhadamente, ou mais do que o nada que já se disse (PESSOA, 1966, p.160)

Para além da Unidade harmoniosa do Todo com as partes, as linhas finais acentuam a dimensão esotérica quando é dito "um poema é um ente vivo", "só um ocultista” é que compreenderá, o que pode parecer excessivo. Mas sabemos como em Fernando Pessoa a sua apetência para o mistério e a mistagogia, mas também para a Verdade e a Iniciação o levou ao longo da vida a interessar-se sempre pelo lado interno ou subtil da vida e a estudar o ocultismo, e a obter resultados e convicções sobre a alma humana, a alma das coisas, das paisagens e da nação, tendo-nos deixado muitos textos, alguns ainda inéditos, nomeadamente nessa dimensão de ocultista ou de iniciado da Ordem Templária de Portugal, conforme no fim sua vida se definiu em nota biográfica, provavelmente face à opressão que o Estado Novo começava contra o livre pensamento e as Associações Secretas.

Voltemos agora, lembrando-nos do seu valioso dito: «A única realidade é o eterno presente filosoficamente, o imortal Agora» (in Fernando Pessoa. Textos Filosóficos, por António de Pina Coelho), ao início do artigo final da Exílio, no qual "Fernando Pessoa, Sensacionista", como vemos assinar no fim, aprecia o que fora Orpheu e o que era o Movimento Sensacionista. Transcrevemos na íntegra e comentaremos, realçando de antemão palavras como adeptos, sensibilidades acordadas, espíritos, Deus, génios:

\section{MOVIMENTO SENSACIONISTA}

Apesar de a sua tarefa ser a da reconstrução da literatura e da mentalidade nacionais, o Movimento Sensacionista vai dia a dia colhendo força, rasgando caminho, florindo em novos adeptos e sensibilidades acordadas.

Desde a data, gloriosa para as nossas letras, em que, com a publicação de "Orpheu”, um oásis se abriu no deserto da inteligência nacional, os Espíritos, a quem Deus concedeu que com a sua sensibilidade espontânea iniciassem o Sensacionismo, vêem, com patriótico agrado, de todos os solos do país, de todos os estratos da cultura, brotar poetas da prosa e do verso, que, levemente uns, vincadamente outros, alguns com consciência, outros como que malgré eux, vêm aderir de inspiração aos princípios que constituem a atitude sensacionista. Por toda a parte a sociedade ocultamente constituída pelas inteligências portuguesas vai sendo ensopada em sensacionismo. Na mocidade que começa a escrever-se, os poucos que mostram esperanças de dar fruto intelectual não florescem senão a dentro do Sensacionismo. 
Ninguém hoje, entre os escolares que se prezam, admira ou imita os nossos clássicos ou os clássicos dos nossos jornalistas.

Tudo isto representa - outro sentido não pode ter - uma instância da Hora da Raça, que, sentindo a necessidade de realizar Cosmópolis em si, se vira para o único núcleo de artistas que, além de darem ao seu instinto de Chefes a garantia primária de serem quase todos homens de génio, que tomaram de nascença nas mãos o pendão da Raça (há tanto tempo bolorejando no túmulo de Camões, de Garrett ou de outros bric-à-brac), representam, manifestamente, uma plêiade luzida que nas suas obras enfeixa, com o máximo utilizável do sentimento português, o máximo aproveitável nas actuais correntes europeias.

O Sensacionismo surgiu, pois, como primeira manifestação de um Portugal-Europa, como a única «grande arte» literária que em Portugal se tem revelado, livre da estreiteza crónica que tem prendido no seu leito de Procustes todos os nossos impulsos estéticos, desde a tísica espiritualidade que subjaz ao pseudopetrarquismo dos tristes poetas da nossa Renascença, até à seca emotividade em torno à qual nucleou o neo-huguismo (grande embora) do actual chefe honorário da intelectualidade portuguesa [Guerra Junqueiro, de quem é inserida na revista uma fotografia artística realizada por Victoriano Braga].

Sintético assim, o Sensacionismo triunfou. Primeiro pelo escândalo, que outro não podia ser o triunfo entre os feirantes que ergueram barracas no terreno desocupado da nossa crítica. O nosso meio jornalístico e "literário", acostumado ou a ser latoeiramente estrangeiro, ou a ser nacional no nível da Praça da Figueira, deu a «Orpheu» a única honra que em tais almas cabia conferir - a da sua invertebradamente espontânea, surpreendentemente sincera aversão. Assim, no que facto público, se lançou o Sensacionismo. A única propaganda que se fez foi não se fazer propaganda nenhuma. Grátis lhe fez esse frete a amabilidade involuntária dos críticos.

Depois, seguro e certo como uma maré que sobe, começou o triunfo nos espíritos. De alma a alma, das aproveitáveis, o Sensacionismo correu. Chegou, viram-no, e venceu. E este muito é o pouco que são todos os princípios. Hoje é já uma vitória; amanhã será uma nacionalidade (1982, p.46-7)

Talvez destaquemos neste texto, como primeiro aspecto de maior sentido oculto e de intensidade espiritual, a noção de génio, algo que Fernando Pessoa sentia ser e sobre a qual especulará bastante ao longo da vida, aqui referenciada em alguns seres espontaneamente e por Deus chamados a esta missão de renovação da literatura e da mentalidade nacional, fazendo-a sair de uma "tísica espiritualidade" e de uma crítica ao nível de barraca de feira, graças à síntese do sentimento português com o que há-de melhor com as correntes europeias.

Por isso Fernando Pessoa neste texto final assume-se primeiro como doutrinador do movimento sensacionista que sente 
e vizualiza quase que messianicamente no seu crescimento, e em segundo como crítico, em geral do ambiente literário nacional e em particular dos novos sensacionistas, os dois poetas que examina.

Não podemos deixar de relacionar este texto com os artigos de 1912 na revista Águia de análise à nova poesia portuguesa onde concluía muito racionalmente a vinda para breve de um super-Camões, e apelava com fé e determinação de "pensamento e acção (...) para que nenhuma das nossas almas falte à sua missão de hoje, de criar o supra-Portugal de amanhã" (PESSOA, 2006, p.27)

$E$ embora não $o$ assumindo claramente individualmente, assume-o como líder da geração e do movimento, e saberemos como durante toda a sua vida ele foi hipostatizando-se em heterónimos e em grupos, movimentos e ordens que culminam na sua nota biográfica final afirmando-se cristão gnóstico e iniciado directamente por mestre a discípulo na Ordem Templária de Portugal.

Mesmo a Mensagem do fim da sua vida já se sente pulsar neste texto de $1916 \mathrm{em}$ pleno sensacionismo adolescente, pois tanto Fernando Pessoa começou a trabalhar nela muito cedo pois o seu desabrochar de poeta místico e patriótico foi muito precoce, assimilando depois, como ele, afirma conhecimentos ocultistas, rosacruzes, templários e maçónicos que de certo modo são essenciais e estruturantes de Fernando Pessoa na sua vida e obra e nos desafiam, portanto, a sondar tais arcanos com imparcialidade, serenidade e profundidade, pois como ele bem doutrinou a intuição, fundamental na obra criadora e do génio, éjá um sentido espiritual desenvolvendo-se e para o qual a iniciação ou o caminho iniciático se foi constituindo e transmitindo, e que ele em tantos momentos e textos especulou e aprofundou.

O segundo aspecto que destacaremos é a afirmação: "Por toda a parte a sociedade ocultamente constituída pelas inteligências portuguesas vai sendo ensopada em sensacionismo".

Esta ideia e frase será mantida ao longo dos anos e terá uma das suas avatarizações, em 1934, um ano antes de morrer, quando na entrevista a Augusto da Costa, inserida na sua obra Portugal Vasto Império, à pergunta qual a melhor propaganda para levantar a moral da nação, depois de referir que a humanidade odeia a verdade e é conduzida por mentiras, responde que existe

o mito sebastianista, com raízes profundas no passado e na alma portuguesa. Nosso trabalho é pois mais fácil; não temos que criar um mito, senão que renová-lo. Comecemos por nos embebedar desse sonho, por o integrar em nós, por o encarnar" (PESSOA, 1979, p.100)

Estas afirmações tem por detrás delas algumas concepções ou doutrinas ocultas, tais como a da grande alma portuguesa, e a dos artistas, criadores, heróis, líderes ou iniciados (e daqui o seu interesse grande pelas ordens iniciáticas e em particular pelo que conseguiu compreender e intuir da Ordem Espiritual de Portugal) que tentam fazer agir a massa mais amorfa, ou acordar almas e sensibilidades e entusiasmando-as ou inspirando-as de acordo com os desígnios 
superiores do destino ou da missão de cada um ou de cada nação e época.

Esta mesma visão está presente na famosa carta ao Conde de Keyserling (publicada pela $1^{a}$ vez em 1988, no livro A Grande Alma Portuguesa) na qual lhe explica a existência de um nível oculto da Alma Portuguesa com os seus movimentos históricos, e será com ela que terminará a Mensagem quando a "Hora Absurda" sentida na revista Exílio no poema, e no final da crítica como "instância da Hora da raça", se metamorfoseiam, face ao "Ninguém sabe que coisa quer,/ Ninguém conhece que alma tem,/ Nem o que é o mal nem o que é o bem (...) Ó Portugal, hoje és nevoeiro"(PESSOA, 1999, p.89), no É a Hora, iniciática, axial, do imortal agora, e destinada aos irmãos e irmãs, tal como reafirma com a expressão final "Valete, Fratres", assim se perenizando o anel da graça libertadora, anunciado no começo da Mensagem pelo "Benedictus Dominus Deus noster qui dedit nobis Signum", e que Exílio de Augusto de Santa-Rita nos transmite por ocultos modos nos signos e textos que harmoniosamente a integram e nos ajudam a reintegrar.

\section{REFERÊNCIAS}

EXÍlLIO. Lisboa: Contexto, 1982.

MONTALVOR, Luís de. Introducção. In: Orpheu. $4^{\mathrm{a}}$ reed. Lisboa: Ática, 1984. v.1. pp.1112.

Tentativa de um Ensaio sobre a Decadência. In: Centauro. Lisboa: Contexto, 1982. pp. 7-12.

PESSOA, Fernando. A Grande Alma

Portuguesa. (Textos inéditos estabelecidos e comentados por Pedro Teixeira da Mota). Lisboa: Edições Manuel Lencastre, 1988.

\section{A Nova Poesia Portuguesa}

Sociologicamente Considerada. Lisboa: Nova Ática, 2006.

. Obra poética. (Organização, introdução e notas de Maria Aliete Galhoz). Rio de Janeiro: Nova Aguilar, 1999.

Páginas Íntimas e de AutoInterpretação. (Textos estabelecidos e prefaciados por Georg Rudolf Lind e Jacinto do Prado Coelho.) Lisboa: Ática, 1966.

Rosea Cruz (Textos estabelecidos e apresentados por Pedro Teixeira da Mota). Lisboa: Edições Manuel Lencastre, 1989.

Sobre Portugal - Introdução ao Problema Nacional. Fernando Pessoa (Org. Joel Serrão.) Lisboa: Ática, 1979.

Recebido para publicação em 11 nov. 2016. Aceito para publicação em 20 jan. 2016. 